\title{
A Pilot Study to Show the Association of Intra Abdominal Length of Esophagus with Gastro Esophageal Reflux (GER) in Early Infancy
}

\author{
Vivek kumar ${ }^{1 *}$, Ashutosh Arya ${ }^{2}$ and Vijay Bhaskar ${ }^{3}$ \\ ${ }^{1}$ Classified specialist Pediatrics and Pediatric Cardiologist Army hospital R\&R, India \\ ${ }^{2}$ Classified specialist Radiology 5AFH, India \\ ${ }^{3}$ Classified specialist Social and Preventive Medicine, India
}

Submission: January 27, 2017; Published: February 27, 2017

*Corresponding author: Dr Vivek kumar, Classified Specialist Pediatrics, Pediatric Cardiologist, Army hospital R\&R, Dhaula kuan, Delhi cantt, New Delhi-110010, India, Tel: 91-7042743322; Email: vk3532@gmail.com

\begin{abstract}
Aim: The aim of this study is to show that small intra abdominal length of esophagus on an ultrasound is associated with increased severity of Gastro esophageal Reflux (GER) in early infancy.

Method: A prospective case control study conducted on study group $\mathrm{n}=20$ (infant up to 6 months presenting with perturbing regurgitation /vomiting or features of Gastro esophageal Reflux disease (GERD) and control group $n=10$ (asymptomatic infant up to 6 months reporting for routine immunization/some minor complaints). Ultrasound study was carried for 10 minutes after giving weight specific milk. Parameters noted were intra abdominal length of esophagus, and number of GER episodes (mild 1-3, moderate 4-6 and severe $>6$ ) detected in lower $1 / 3$ of esophagus.

Results: Mean intra abdominal length of esophagus in case cohort was $18.84 \pm 3.50$ and GER episodes $3.4 \pm 2.18$ while in control it was $19.6 \pm 3.5$ and $2 \pm 0.67$ respectively. Pearson correlation in case cohort showed a strong negative association of -0.56 which meant that as length decreased GER episodes increased while in control cohort it was +0.185 which meant no association.
\end{abstract}

Conclusion: This pilot study shows that shorter intra abdominal length of esophagus is associated with increased severity of GER.

Keywords: Intra abdominal length of Esophagus; Gastro esophageal Reflux; Gastro esophageal Reflux Disease

\section{Background}

GER is backward flow of stomach content in to the esophagus. It is very common in infants because of physiological immaturity of lower esophageal sphincter (LES). LES is determined by abdominal length of esophagus and tone. Competent LES prevents severe and recurrent GER. GER presents as regurgitation and spit up and peaks at 1-4 month of age. Prevalence of GER which is $65 \%$ in early infancy decreases to $1 \%$ by one year of age [1,2]. If GER is associated with symptoms of wheezing, apnea and acute life threatening events (ALTE) then it is called GERD.

Methods of detection of GERD in infants are difficult and involve invasive and tedious procedures like $\mathrm{pH}$ metry, impedance metry and technetium scan. Simple noninvasive ultrasound can detect abdominal length of esophagus, number of episodes of GER and hiatal hernia. Above can be correlated clinically. We under took this pilot study to demonstrate that short abdominal length of esophagus is associated with increased episodes of GER.

\section{Method}

This is a prospective case control study on infants up to 6 months

\section{Study cohort $n=20$; Control cohort $n=10$}

\section{Inclusion criteria}

A. Presenting in Outpatient with severe perturbing vomiting/regurgitation post feed otherwise no illness.

B. Presenting with features suggestive of GERD.

\section{Exclusion criteria}
A. Severe illness
B. Patients with neuromuscular disorder 
Infants reporting for immunization and otherwise offering no complaints were taken as control. All infants underwent ultrasound examination for 10 minutes after ingestion of weight specific milk. Abdominal length of esophagus was measured in a calm infant during exhalation from the point of entry in to abdomen to the base of gastric folds. Following parameters were noted Intra abdominal length of esophagus, number of episodes of GER in the lower $1 / 3$ of esophagus. Birth weight and present weight was recorded. Features of GERD were recorded.

The result showed case cohort $n=20$ with M: F 1:2.3. Age of presentation varied from neonatal age group to 4 month of age. Two had presented with GERD (one with recurrent wheeze and one with ALTE). Mean length of abdominal esophagus was $18.84 \mathrm{~mm}$ SD 3.50 while mean episodes of GER were $3.40 \mathrm{SD}$ 2.18. Out of seven infants who were put on syrup domperidone $@ 0.1 \mathrm{mg} / \mathrm{kg} / \mathrm{dose} 6$ hourly for severe episodes and parents anxiety all showed 50-75\% improvement subjectively. Rest were assured and on follow up showed improvement.

Control cohort $n=10$ with M: F 1:1. This group showed mean length of esophagus as $19.6 \mathrm{~mm}$ SD1.35 and mean of GER episodes were 2 SD 0.66. Pearson Correlation had a negative association in case cohort which showed that shorter abdominal length of esophagus was associated with increased number of GER episodes. While control cohort showed no such association. No infant showed failure to thrive (Figure 1).

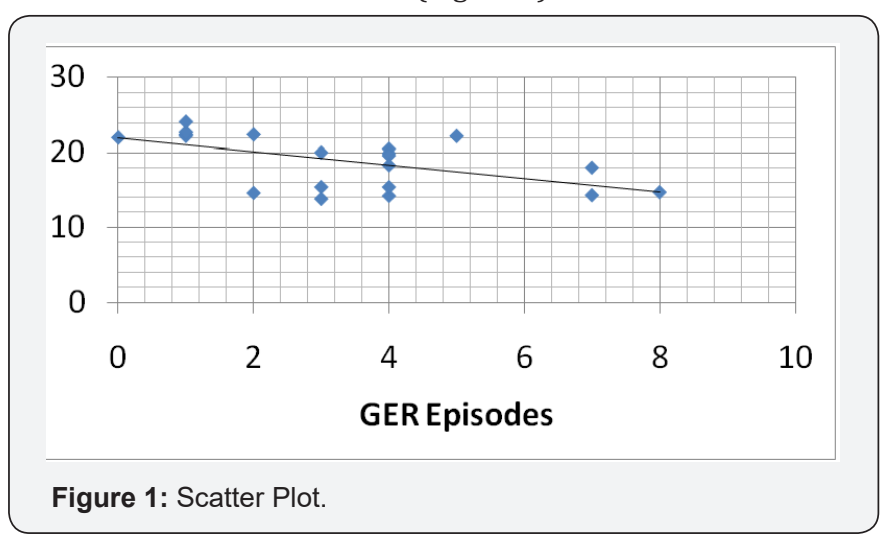

Scatter plot showed negative association between abdominal length of esophagus and GER episodes.

\section{Discussion}

Regurgitation and benign vomiting is very common in infants more so in first 6 months of life. This mainly happens in infants because of fluid diet, lying position and shorter intra abdominal length of esophagus and generally considered physiological. When it produces symptoms like apnea, recurrent wheeze, esophagitis and failure to thrive it is termed as GERD. Diagnosing GER and GERD in an infant is difficult. Methods like pH metry considered gold standard is invasive and time consuming so are the other modalities like barium swallow and impedance metry.
Ultrasound examination with sensitivity of 94\% [3] for detecting GER and abdominal length of esophagus has been suggested by Koumanidou et al. [4] in their retrospective case control study on 258 neonates [3].Similar study was done by Dehdashti et al. [5] on 235 infants aged 3-4 months [4]. Both authors recommend a simple sono graphic assessment for abdominal length of esophagus and number of episodes of GER noted in lower $1 / 3$ esophagus. They have concluded that the shorter length of abdominal esophagus is associated with more number of refluxes. Only disadvantage is that it does not detect grade 4 pharyngeal reflux.

Ours is a pilot study done on a cohort of 30 infants (case $n=20$ and control $n=10$ ) up to 6 months. Case cohort showed a linear relation between shorter abdominal length of esophagus and number of episodes of GER. Two infants with GERD showed similar relation. Seven infants who were given syrup domperidone showed appreciable results subjectively. None of the infants showed failure to thrive in spite of severe regurgitation. To conclude ultrasound examination should be considered for detecting GER and GERD in infants because of the convenience and simplicity of the test and easy objective interpretation. it is not required in every case of regurgitation but severe distressing episodes or case with ALTE(Acute life threatening events) warrants one sono graphic assessment which can also help in prognostication. Drawback of this pilot study was lack of comparison with standard tests like impedance/pH metry.

\section{What This Study Adds}

A. Shorter abdominal length of esophagus sono graphically shows a linear relation with increased number of GER.

B. Silent GERD presenting as ALTE (Acute life threatening events) can be diagnosed by this method.

\section{References}

1. Orenstein SR (1997) Infantile reflux: different from adult reflux. Am J Med 103(5): 114-119.

2. Vandenplas Y, Lifshitz JZ, Orenstein S, Lifschitz CH, Shepherd RW, et al. (1998) Nutritional management of regurgitation in infants. J Am Coll Nutr 17(4): 308-316.

3. Hirsch W, Kedar R, Preis U (1996) Color Doppler in the diagnosis of gastro esophageal reflux in children: comparison with $\mathrm{pH}$ measurements and B-mode ultrasound. Pediatr Radiol 26(3): 232 -235.

4. C Koumanidou, M Vakaki, G Pitsoulakis, A Anagnostara, P Mirilas (2004) Sono graphic Measurement of the Abdominal Esophagus Length in Infancy: A Diagnostic Tool for Gastro esophageal Reflux . AJR 183(3): 801-807.

5. Dehdashti H, Dehdashtian M, Rahim F, Payvasteh M (2011) Sonographic measurement of abdominal esophageal length as a diagnostic tool in gastro esophageal reflux disease in infants. Saudi J Gastro enterol 17(1): 53-57. 
(C) This work is licensed under Creative

BY DOI:10.19080/AJPN.2017.03.555614
Your next submission with Juniper Publishers will reach you the below assets

- Quality Editorial service

- Swift Peer Review

- Reprints availability

- E-prints Service

- Manuscript Podcast for convenient understanding

- Global attainment for your research

- Manuscript accessibility in different formats

( Pdf, E-pub, Full Text, Audio)

- Unceasing customer service

Track the below URL for one-step submission https://juniperpublishers.com/online-submission.php 